Chapter 21

\title{
Brain Function in Fibromyalgia: Altered Pain Processing and Cognitive Dysfunction
}

\author{
Francisco Mercado, Paloma Barjola, \\ Marisa Fernández-Sánchez, Virginia Guerra and \\ Francisco Gómez-Esquer
}

Additional information is available at the end of the chapter

http://dx.doi.org/10.5772/56495

\section{Introduction}

Since several decades ago chronic pain understanding has become in one of the most intriguing challenges for health professionals (rheumatologists, psychologists, physiotherapists, anaesthesiologists, pharmacologists, etc). Different reasons are behind that traditionally poor knowledge about the etiology, mechanisms and treatment of chronic pain. Pain has been very often considered as a peripheral entity in which peripheral causes, such as inflammation and structural joint damage, have been only explored. Thus, difficulties to explain painful symptomatology associated to chronic pain patients, such as the great discordance between pain complaints or severity and their supposed peripheral causes, have lead to the development of investigations to advance in the knowledge of pain mechanisms in chronic pain diseases (p.e., non-inflammatory conditions), such as it occurs in fibromyalgia (Buskila, 2009). These studies have highlighted both the important role of central pain-processing mechanisms and its evidently multifactorial status (Lee et al., 2011; Schweinhardt et al., 2008).

Fibromyalgia (FM) constitutes a chronic syndrome mainly characterized by the presence of widespread and diffuse pain (Fan, 2004). Traditionally, FM diagnosis has been only established by the presence of widespread pain during at least three months and tenderness to palpation at specific locations (the so-called 'tender points') following the American College of Rheumatology criteria (ACR, Wolfe et al., 1990). refer to 18 places symmetrically distributed at both sides of the body where patients feel pain when a weak pressure is applied on them with the thumb of the examiner (lower than $4 \mathrm{~kg} / \mathrm{cm} 2$, see Figure 1). Currently, this syndrome is affecting between $2-4 \%$ of population (between 80 and 90 percent of patients diagnosed with FM are 
women) being one of the most common causes of pain and disability. However, the biological bases for the clinical characteristics of FM remain elusive (Martínez-Lavin, 2004; Montoya et al., 2005; Vierck, 2006). Studies have focused particularly on the mechanisms underlying pain perception, and central signals processing. FM patients refer two kinds of somatic sensations: a) enhanced pain sensitivity to painful stimulation (hyperalgesia) and b) a painful response to a normally innocuous stimulus (allodynia). Central augmentation mechanisms underlying this amplified pain perception have been investigated using advanced imaging techniques that aim to localize and describe alterations in specific areas of the brain. Indeed, scientific evidence suggests that central abnormalities in the processing of pain signals seem to be responsible of such altered pain manifestations (diffuse hyperalgesia and allodynia) in FM (Staud et al., 2004; Thieme et al., 2005).

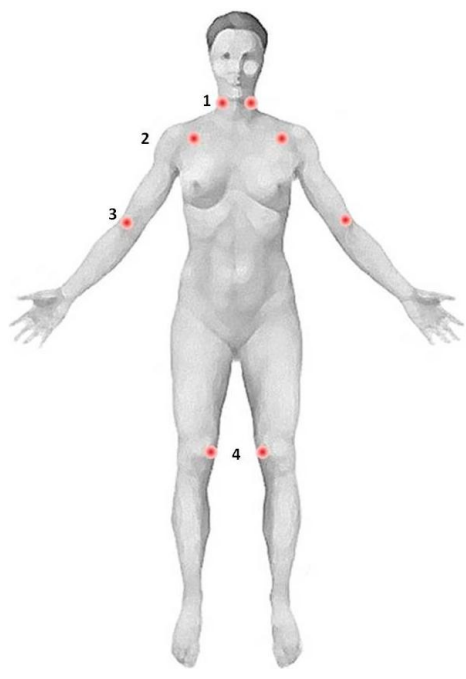

(a) Anterior vew

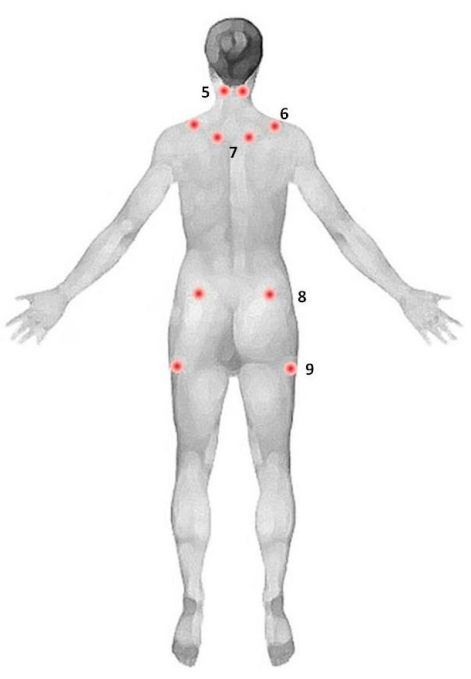

(b) Posterior vew

Figure 1. Bilateral tender point locations for the traditional ACR diagnosis criteria for Fibromyalgia (adapted from Wolfe et al., 1990). (a) ANTERIOR VIEW: 1. Low cervical: the anterior aspects of the intertransverse spaces at C5-C7, 2. Second rib: the second costochondral junctions, lateral to the junctions on upper surfaces, 3 . Lateral epicondyle: $2 \mathrm{~cm}$ distal to the epicondyles, 4. Knee: the medial fat pad proximal to the joint line. (b) POSTERIOR VIEW: 5. Occiput: the suboccipital muscle insertions, 6. Trapezius: the midpoint of the upper border, 7. Supraspinatus: above the scapula spine near the medial border, 8. Gluteal: upper outer quadrants of buttocks in anterior fold of muscle, 9. Greater trochanter: posterior to the trochanteric prominence.

Additionally, people with FM frequently experience a great amount of other accompanying symptoms apart from pain, such as physical complaints (stiffness, fatigue, sleep problems), affective disorders (anxiety or depression) and cognitive dysfunctions (failures in memory, attention and concentration). In fact, cognitive failures represent one of the most important complaints of these patients, recently denominated as fibrofog (Glass, 2010), leading to produce even greater functional impact than pain itself (Glass, 2009). Based on growing evidence from 
neuropsychological and neuroimaging studies, ACR criteria have been recently modified including the cognitive dysfunction and affective disturbances, among other symptoms, as key factors for FM diagnosis (Wolfe et al., 2010). These findings, along with the lack of peripheral signs of inflammation to account for pain, support the hypothesis that FM is a syndrome characterized by an abnormal processing of information at the level of central nervous system. Therefore, psychoneurobiologic dysfunctions seem to be crucial for trying to explain this multifactorial and still not fully understood clinical condition (Lee et al., 2011; Schweinhardt et al., 2008), but also to give response, at least partially, to the appearance and maintenance of both pain-related and cognitive symptomatology. In the following review, we will try to describe what is currently known about the cerebral mechanisms in pain processing, the neural correlates of cognitive dysfunction and the pathogenesis of FM, with special attention to the genetic basis.

\section{Cerebral pain processing in fibromyalgia}

Fibromyalgia is considered a chronic pain syndrome which cause (still remain elusive) does not have been found in localized lesions, inflammatory processes or damage to the joints, muscles or other tissues. Experimental evidence indicates that pain processing abnormalities leading to maintenance of pain showed by these patients (e.g., hyperalgesic states) could be due to both central sensitization mechanisms and specific defects in central pain processing related to the loss of normal activity of descending pain-inhibitory (e.g., serotonin-norephinephrine-opioidergic) pathways (Ceko et al., 2012; Lee et al., 2011). Central sensitization related to diffuse hyperalgesia and allodynia is functionally linked to central nervous changes caused by the release of different excitatory neurotransmitters such as serotonin, substance $\mathrm{P}$ or glutamate, among others. Through their action on specific receptors (e.g., NMDA) those neurotransmitters might produce enhanced and amplified responses at central nervous level (Woolf, 2004). Specifically, central sensitization can also produce an augmentation of receptive fields in neurons belonging to spinal cord and peripheral fibers. Other neurophysiological indices found in FM patients have involved elevated levels of substance P and serotonin metabolites in cerebrospinal fluid compared with healthy people (Russell et al., 1994; Russell et al., 1992), along with a diminished level of neurotransmitters, which dampen pain sensitivity response (e.g., norepinephrine) suggesting again defects in central pain processing (Russell et al., 1992). Behaviourally, the phenomenon of central sensitization is characterized by lower thresholds in pain perception, pain tolerance and by an enhancement of noxious sensations as a consequence of repeated stimulation, as it occurs in temporal summation (Staud et al., 2003). Additionally, whereas the activation of NMDA receptor channels produces central sensitization, the administration of NMDA receptor antagonists such as ketamine reduces significantly pain perception and facilitates the inhibition of hyperalgesia indices (i.e., temporal summation) in FM patients (Price et al., 2002; Graven-Nielsen et al., 2000). Neuroimaging studies have demonstrated the presence of an augmented activation pattern of pain processing involving several cortical and subcortical regions in FM (Gracely et al., 2002). This 
augmented pain processing pattern resulted in response to the same perceived intensity of painful stimulation compared to control participants (Gracely et al., 2002; Cook et al., 2004).

Pain descending inhibitory pathways start from different cerebral levels localized on the brainstem, bulbar region, diencephalic structures and cortical areas. These pathways constitute one of the most important mechanisms involved in the pain perception modulation of sensory information in the dorsal horn of spinal cord. Experimental evidence has described defects in those pain inhibitory pathways leading to a loss of descending endogenous analgesia and the maintenance and enhancement of painful sensations in patients with FM (Julien et al., 2005). These results have been found using different types of acute noxious stimulation. Staud and colleagues (2003) highlighted the presence of diminished pain inhibitory mechanisms in response to hot water in a sample of women with and without FM. Previous studies applying tonic thermal stimulation and by using a tourniquet to produce ischemic pain showed evidence for the defects in descending inhibitory pain activity in FM (Lautenbacher et al., 1997; Kosek et al., 1997). In the same line, diminished periaqueductal gray responses to heat stimulation have been reported in these patients when it was compared with the activity of healthy participants (Cook et al., 2004). Periaqueductal gray region (PGR) has been described as an important structure involved in both ascending and descending pain processing signals (Stahl, 2009). Descending projections from PGR to dorsolateral pontine structures act inhibiting pain signals from peripheral afferent neurons in the dorsal horn of the spinal cord through the release of noradrenaline and serotonin neurotransmitters. Thus, the observed lack of activation within PGR in FM could lead to a loss of descending analgesia enhancing chronic responses of hyperalgesia in these patients (Herrero et al., 2000). Exposed findings demonstrate the main role of abnormalities in central mechanisms as an important key to understand chronic pain in the FM syndrome (Abeles et al., 2007; Bennett, 2005; Lee et al., 2011).

\subsection{Morphological brain changes associated with abnormal pain processing in fibromyalgia}

Experimental evidence focused on the study of brain areas involved in the processing of painful stimulation has revealed that chronic pain patients show an abnormal activation pattern at specified brain regions (e.g., Kwiatek et al., 2000). Neuroimaging research and its application to the study of pain, has facilitated the identification of a brain network involved in pain processing that has been denominated as 'pain matrix', comprised, among others, by different cortical and subcortical regions: for example, somatosensory regions, insular areas and anterior cingulated cortices (ACC) (Bushnell et al., 2005; Tracey \&Mantyh, 2007). Although recently the referred pain matrix has been functionally redefined not only as a pain processing network but also as salience detection system (Iannetti et al., 2010; Legrain et al., 2011; Tracey \& Johns, 2010), the role played by somatosensory cortices and other cortical regions, such as posterior parietal cortex or prefrontal areas in the processing of nociceptive signals and in the affective/cognitive modulation processes of pain perception, has been extensively documented (Lorenz et al., 2003; Peyron et al., 2000; Rolls et al., 2003; Sawamoto et al., 2000; Singer et al., 2004; Wiech et al., 2008). For instance, attentional modulations on pain perception have been seen in the increase and/or decrease of activations within insula and ACC (Valet et al., 2004; Wiech et al., 2005). 
Chronic pain diseases are commonly characterized by an abnormal functioning when painful events are processed and as a consequence of it, chronic pain has been understood as an altered perceptual state (Apkarian et al., 2005). Nevertheless, chronic pain is also defined as a dysfunctional condition derived from the appearance of structural brain changes that become more generalized as a function of the years suffering from pain (Baliki et al., 2011). Such changes could cause a dysfunctional neural reorganization affecting brain dynamics (Baliki et al., 2008; Tagliazucchi et al., 2010). Evidence accumulated from the last years through the use of different brain imaging methodologies supports the presence of changes in the brain of FM patients (i.e., structural and functional changes) (García-Campayo et al., 2010; Gracely et al., 2011), although such changes are heterogeneous and a unique interpretation about its clinical meaning remains still unclear. Altered brain morphology was reported by voxel-based morphometry (VBM) studies showing that FM patients had less grey matter density than healthy subjects in several brain regions including insula and ACC (Kuchinad et al., 2007). However, grey matter increase in other cerebral areas belonging to the somatosensory system, such as the Striatum or in those other ones involved in the cognitive modulation of pain (i.e., Orbitofrontal CortexOFC) have been seen in patients suffering from FM (Schmidt-Wilcke et al., 2007). Further findings combining diffusion-tensor imaging (DTI) and VBM methodologies have described not only a reduction in grey matter density in FM but also abnormalities in white matter microstructure within thalamus and insular cortex, being highly correlated with the intensity of main FM symptoms (Lutz et al., 2008). Specifically, patients showing higher pain intensity scores were characterized by DTI measurements indicating changes within superior frontal gyrus (SFG). Moreover, changes in SFG and ACC were positively correlated with increased fatigue and self-perceived physical impairment. Affective symptoms defined by higher scores in posttraumatic stress scales were negatively correlated with microstructural changes represented by values of fractional anisotropy (FA) in FM. In this line, Hsu and colleagues (2009) reported decreased grey matter volume in the left anterior insula for patients with FM compared to healthy control participants. This difference in grey matter volume disappeared when the presence of affective disorders in FM patients was controlled. Thus, grey matter volume within this area was inversely correlated with scores in trait anxiety, highlighting the important role of affective disturbances in the explanation of these morphological brain changes. More recent studies have documented that patients with FM syndrome show grey matter atrophy within ACC, mid-cingulate Cortex (MCC) and insular cortex, but affective symptoms like depression are not related to these grey matter changes (Robinson et al., 2011). Along with emotional symptomatology, cognitive alterations in FM have been correlated with changes in grey matter values (Luerding et al., 2008). They found that working memory performance in FM patients was highly and positively correlated with decreased grey matter values within medial prefrontal cortex (MPFC) and ACC, showing that cognitive deficits in FM are associated with changes in brain morphology.

Therefore, mentioned brain abnormalities in the traditionally denominated pain matrix regions might contribute to the alteration of pain processing in FM patients, but they could also affect other domains such as cognitive and affective symptomatology. In fact, it has been proposed that pain and cognitive impairment in FM may co-occur sharing underlying neural networks (Luerding et al., 2008), and as a consequence of it, performance derived from carrying out a 
cognitive task when individual is in pain might decrease due to the availability of neural resources is limited and they are invested in pain processing (Seminowicz and Davis, 2007). Additionally, the presence of chronic pain along the years might contribute to the appearance of changes in the brain leading to abnormal activation of brain regions that could exacerbate pain itself and also disturb cognitive function in FM (Kuchinad et al., 2007). Although structural neuroimaging evidence supports the association of chronic pain in FM with grey matter abnormalities, future investigations should be projected to confirm and extend these findings.

\subsection{Functional brain changes associated with abnormal pain processing in fibromyalgia}

Beyond morphological brain changes, functional imaging investigations have revealed abnormal activation patterns at specific cerebral regions in FM patients (e.g., Cook et al., 2004), however, these anomalies in pain processing are not always circumscribed to activation of brain areas intimately or traditionally related to pain. It has been observed during different experimental situations: in response to painful stimulation, when somatosensory (not painful) information has to be processed and even during resting-state conditions. One of the first neuroimaging studies conducted to investigate such issues demonstrated enhanced brain activation in many regions (i.e., primary and secondary somatosensory cortex, ACC, insula) for FM patients in response to similar levels of pressure stimulation to that one applied to control subjects (Gracely et al., 2002). Moreover, when subjectively painful conditions were established to be comparable (i.e., intensity of stimulation was significantly greater to healthy people than patients for provoke a similar subjective level of pain perception) similar brain activation patterns were found between both patients and control groups. These results indicate that central sensitization defects could be explaining the presence of such augmented activation pattern for painful signals in FM. More recent studies aimed to test the hypothesis of central augmentation pain processing in FM have confirmed and extended those findings (Maestú et al., 2013). Abnormal brain activation of different regions related to the affective/ motivational components of pain processing was found in patients with FM during a pain situation induced by a small incision into the skin (Burgmer et al., 2009). Thus, enhanced activations were observed within frontal and cingulated cortices, along with supplementary motor areas. Such altered responses were especially prominent during the pain anticipation period. Additionally, that altered temporal BOLD-signal pattern was found as specific for FM patients when they were compared to other patients suffering from rheumatoid arthritis (Burgmer et al., 2010). It leads to think that fronto-cingulated regions could play a key role as central mechanisms of pain processing responsible to the maintenance and exacerbation of chronic pain in FM.

Previous investigations had already given data about the role of cognitive, affective and social factors on pain processing in FM. Neural responses to somatosensory stimuli can be modulated by cognitive and emotional factors (Cook et al., 2004). Specifically, the catastrophyzing thinking style has been associated with enhanced cerebral responses to pain. Cortical areas involved in pain expectancy or pain-related attention (ACC, MPFC or dorsolateral prefrontal cortex -DLPFC-) showed more intense activity in FM patients who scored high in catastrophizing (Gracely et al., 2004). Affective conditions such as comorbid depression, seem to have influence in the activation of amygdala, but not of somatosensory brain regions during pain processing information (Giesecke et al., 2005). Event-related potentials (ERP) studies have also 
provided data demonstrating abnormal emotional modulation of brain processing in response to somatosensory/non-painful stimuli (Montoya et al., 2005). Somatosensory components (i.e, P50) displayed largest amplitudes when FM patients were introduced within a negative emotional context created with unpleasant slides. The influence of the emotional context was also described during the processing of painful stimulation (Montoya et al., 2004). At the same time, the presence of significant others during the application of painful stimulation was found as a social factor that diminish magnetic brain responses and subjective pain in FM patients compared to control participants (Montoya et al., 2004). Other works have observed that FM patients show a significant enhancement of brain activation within regions involved in the emotional/cognitive aspects linked to pain processing as compared to control subjects, given a painful stimulation (Burgmer et al., 2009). Indeed, larger activation within CCA and anterior insula along with more persisting responses in insular cortex were found for FM patients as well (Pujol et al., 2009). It supports the hypothesis that both affective/cognitive and social factors may play a very important role for pain processing in patients with FM.

On the other hand, the role played by several neurotransmitters, such as dopamine or glutamate, which exerts their functions at the level of central neural system, has been also highlighted in the pathogenesis of FM and studied through the use of neuroimaging techniques (Harris, 2010; Stahl, 2009). Different genetic polymorphisms associated with the functional activity of those neuromodulators have been documented (Ablin et al., 2008), as it will be extensively described later. Evidence on altered levels of mentioned neurotransmitters within the brain of patients with FM has recently reported (Harris et al., 2008; 2009). Dysregulation in levels of glutamate, an excitatory neurotransmitter, has been found within the posterior insula of FM patients being such altered levels associated with experimental pain (Harris et al., 2010). Higher concentration levels of glutamate and glutamine were also detected within the amygdala (Valdés et al., 2010) and posterior insula (Fayed et al., 2010). Patients group showed diminished pain thresholds and high scores in pain and tenderness suggesting that neuronal hiperexcitability elicited by the presence of glutamate may lead to an augmented central pain processing. With respect to other neurotransmitters, different investigations have indicated an abnormal dopamine response to pain in FM (Wood et al., 2007b; Wood et al., 2009). It is known that dopamine is a neurotransmitter involved in pain modulation, but whereas general population showed an increase of dopamine release when a painful stimulus was perceived FM patients did not (Wood et al., 2007a). Thus, that deficiency in dopaminergic reactivity might have a relevant impact on the development and maintenance of chronic pain in FM. In fact, some studies have shown reduced presynaptic dopaminergic activity suggesting that such disrupted neurotransmission could prevent for natural analgesia in FM (Wood et al., 2007b). More recent findings have associated alterations in dopaminergic neurotransmission with a decrease in grey matter density within posterior cingulated cortex, ACC and parahippocampal gyri (Wood et al., 2009). Therefore, these data suggest that pharmacological approaches targeted to the specific or combinated use of glutamatergic and dopaminergic treatments may be effective and should be explored (for a review see, Smith-Wilcke \& Clauw, 2010).

Finally, recent investigations postulate that FM could be characterized by an alteration of brain connectivity among different brain networks (Cifre et al., 2012; Napadow et al., 2010). It has been documented that chronic pain produces a disruption in the default mode network (DMN; 
Baliki et al., 2008). Evidence coming from neuroimaging studies reported increased resting state connectivity between insula and other brain networks such as the DMN in FM patients. This connectivity pattern was highly and positively correlated with spontaneous pain (Napadow et al., 2010). In fact, when a sample of patients underwent to an acupuncture treatment aimed to diminish pain perception, the degree of connectivity between insula and DMN was also decreased leading to consider resting state connectivity as an objective marker to assess pain in FM (Napadow et al., 2012). Other studies have confirmed the presence of an altered connectivity pattern among brain regions belonging to pain processing network in FM during rest (Cifre et al., 2012). Indeed, such alteration might be due to slow temporal summation effects evoked by C-fiber pain (Craggs et al., 2012).

\section{Neural correlates of cognitive dysfunction in fibromyalgia}

\subsection{Cognitive complaints in FM}

It has been suggested that FM syndrome is characterized by an abnormal processing of information in the central nervous system (Montoya et al., 2005; Okijufi et al., 2002) affecting the response to somatosensory stimulation (e.g., painful signals) but also to information belonging to other modalities (e.g., visual, auditory, etc). Several studies indicate that apart from pain and other physical symptoms, cognitive failures are referred by these patients as one of the most important complaints (recently denominated as fibrofog; Glass, 2009; Williams et al., 2011), leading to produce even greater functional impact than pain itself (Arnold et al., 2008; Glass et al., 2005). Thus, the incidence rate for memory and concentration difficulties exceeds $90 \%$ in FM, being significantly higher that one ocurred in other chronic pain conditions (Arnold et al., 2008; Mease et al., 2008). Additionally, self-reports of patients support the presence of a higher number of cognitive problems than patients suffering from other chronic pain syndromes (Katz et al., 2004), affecting several cognitive domains (Williams et al., 2011). For example, memory complaints of FM patients were positively correlated with the objective perfomance obtained in tasks which set in motion memory resources (Glass et al., 2005). Moreover, these cognitive difficulties manifest persistently in many of daily activities involving the allocation of attentional control resources such as to remember that they have to call someone the next day or to inhibit thoughts that do not allow them to develop other concurrent daily tasks. Experimental evidence confirms that attention, concentration, episodic memory and verbal fluency are impaired in FM (Glass, 2009) showing that such difficulties in the processing of information constitute a very disruptive symptom for patients who have FM, worsening its quality of life and leading to consider it as an independent symptom (SchmidtWilcke et al., 2010).

\subsection{Neuropsychological and behavioural data on cognitive dysfunction in FM}

Since the beginning of the past decade growing objective evidence based mainly on neuropsychological studies has shown real and significant impairments of cognitive functions in FM (Glass \& Park, 2001; Park et al., 2001). First attempts to characterize dyscognition in FM 
reported deficits in the two declarative memory systems related to the explicit recall of information, episodic and semantic memory. Experimental data revealed poor performance on both standardized (Grace et al., 1999) and non-standarized episodic memory tests (Landro et al., 1997; Grisart et al., 2002). Semantic memory problems have also been documented. FM group showed lower ability for accessing to stored general knowledge than control group when patients were asked to report as many words as they could say starting with a given letter (for example, ' $\mathrm{p}$ ') and belonging to a specific category (for example, 'fruits and vegetables') (Landro et al., 1997; Park et al., 2001). Along with verbal fluency difficulties, a decrease in naming speed (Leavitt et al., 2008) and speed processing (Veldhuijzen et al., 2012) was also found in FM patients. However, those results are not unequivocal since some studies failed to find differences in cognitive function between patients and healthy control participants (Suhr, 2003). This variability could be related to the lack of previous systematic and detailed research, suggesting that cognitive impairment in FM patients is not generalized; rather is specificprocess dependent.

Recent data have suggested that findings on cognitive dysfunction in FM are particularly solid when patients have to deal with tasks demanding for both executive control and working memory resources (Ambrose et al., 2012; Glass, 2010). Impairments in those domains seem to be the key to explain a great part of the cognitive dysfunction in FM. Executive functions (EF) refer to those mechanisms that allow the regulation of both behaviour and other cognitive processes to achieve a specific objective (Muñoz-Céspedes and Tirapu, 2001). Within this theoretical frame, working memory is defined as the support system of those EF aimed to temporarily hold in mind and manage with a variable amount of information (Baddeley, 2000). Thus, working memory dysfunctions have also been seen in FM (Luerding et al., 2008). It has been also observed that patients perform poorly in a variety of tasks involving the allocation of executive control resources to alternate between cognitive sets (Verdejo-García et al., 2009) and to make emotional decisions (Verdejo-García et al., 2009; Walteros et al., 2011) or to face with a task-switching test (Glass, 2006). Tests commonly used to study those executive function processes are Wisconsin Card Sorting Test (WCST) and the Iowa Gambling Task (IGT). Several studies using the Paced Auditory Serial Attention Test (PASAT) have detected a diminished perfomance in FM individuals compared to controls (Leavitt \& Katz, 2006; Munguía-Izquierdo et al., 2008). Other working memory components like response inhibition are also suggested to be impaired in FM (Correa et al., 2011). Very similar results have been found during the performance in those tests with a high degree of ecological validity (Test of Everyday Attention, TEA) that includes everyday attentional tasks (Dick et al., 2008). Working memory components measured by TEA were impaired in FM, especially when stimuli competition had to be solved. In this sense, the fact that attentional control difficulties become more evident during distraction (derived from a situation of stimuli competition) has lead to consider it as a key point to better understand cognitive dysfunction in FM (Leavitt \& Katz, 2006). It was proposed that failures to inhibit competing stimulation might be an explanation for this difficulty; due to FM patients show hypersensitivity to process information coming from any sensorial modality (Geisser et al., 2008). Such general distractibility could be translated into an attentional orientation towards any type of task-irrelevant stimuli (González et al., 2010) leading to difficulties to focalize attention on relevant information. However, recent 
data derived from the use of cognitive inhibition tests indicate that patients with FM do not show a specific problem in such processes (Veldhuijzen et al., 2012).

Although the body of research on cognitive dysfunction in FM has strongly grown in recent years, there are still several unexplored issues in this field of knowledge that should be investigated such as the delimitation of the specific cognitive mechanisms that are altered in these patients. For instance, it is accepted that working memory abilities are impaired in FM, but are different components (e.g., temporal holding of information, inhibition, manage with two concurrent tasks, etc) characterizing working memory equally affected? Kim and colleagues (2012) have indicated that memory is selectively impaired in FM showing the possible existence of a memory dissociation. Data coming from neuropsychological assessments reveal that whereas visuospatial memory abilities are dysfunctional, verbal memory is quite unaffected. Following a similar reasoning, several studies postulate that cognitive dysfunction in FM is restricted to those cognitive mechanisms based on controlled processes (Grisart et al., 2002). However, the presence of a generalized hypervigilance response in FM (Carrillo de la Peña et al., 2006) seems to be under the control of automatic processes, rather than controlled ones (Crombez et al., 2005). Moreover, recent data have demonstrated a reduced performance of patients with FM during an implicit memory task (Duschek et al., 2013). It is the first direct evidence of cognitive disruption associated with processes non-dependent from conscious and controlled resources in FM. Finally, several comorbid symptoms of FM (e.g., anxiety, depression, sleep disturbances, medication, pain, etc) have been associated with a worsening of cognitive dysfunction. Although the impact of affective symptomatology (anxiety and depression) and sleep problems on the cognitive dysfunction in FM might be important, these variables do not entirely explain it (Park et al., 2001; Dick et al., 2008). However, the negative impact of both chronic and acute pain seems to be very robust. When this variable is controlled FM patients show a marked impairment in tasks involving different cognitive domains (Glass et al., 2011; Reyes del Paso et al., 2012; Verdejo-García et al., 2009). Additionally, level of selfreported pain is correlated with cognitive performance in FM (Glass et al., 2005) and it has been highlighted as a mediating variable to explain deficits in self-regulatory processes in these patients (Solberg et al., 2010). Therefore, the role of pain on cognitive disturbances is considered as quite relevant. Nevertheless, the neurocognitive mechanisms by means pain interferes on patient's cognitive function are still unknown.

\subsection{Brain activity related to cognitive dysfunction in FM}

As it was previously indicated, accumulated evidence supports the presence of clear objective impairments in cognitive function of patients with FM. Cognitive dysfunctional pattern associated with FM (i.e., executive control deficits, working memory failures and declarative memory difficulties) points out to the existence of an altered neural substrate, presumably at least within prefrontal regions, such as inferior prefrontal cortex (IPC), MPFC or ACC along with their connexions with temporal and parietal regions (Glass, 2010; Glass et al., 2011). Although studies focused on these neural mechanisms underlying dysfunctional cognitive processes in FM are still surprisingly scarce, new findings cast some light on the possible altered neurocognitive mechanisms. In this sense, neuroimaging investigations have repeat- 
edly showed increased haemodynamic activity at prefrontal regions (i.e., dorsolateral prefrontal cortex -DLPFC-, ventromedial prefrontal -VMPFC- cortex and ACC) during tasks involving working memory and executive control processes (Bunge et al., 2000; Dagher et al., 1999). Moreover, Altamura and coworkers (2007) have highlighted that the right allocation of working memory resources to accomplish a given task depends on prefrontal regions.

Specific data related to FM patients, have found that working memory performance in FM patients was highly and positively correlated with grey matter values within MPFC and ACC, showing that a decrease of grey matter volume within those prefrontal regions is associated with working memory deficits in FM (Luerding et al., 2008). Additionally, recent functional neuroimaging investigations have revealed diminished activations in cortical regions belonging to the inhibition network, such as ACC, mid-cingulated cortex (MCC) and motor processing areas in patients with FM during the performance in a simple go/no-go task (Glass et al., 2011). At the same time, inefficient activations were detected within insular cortex and IFG when patients had to perform on the mentioned response motor inhibition task. It has been suggested that such effects might be explained via either a greater brain recruitment of cortical compensatory regions different from those involved in response inhibition network. Extending such findings, our research group has tried to characterize cognitive inhibition mechanisms, as part of the altered working memory functions, in patients with FM. Patients showed both enhanced P450 amplitudes and brain activations within IFG in response to an emotional Stroop task (Mercado et al., in press). More in detail, symptom-related words were the kind of stimulation that elicited both the greater frontal P450 amplitudes and the higher IFG activations as compared to rest of stimuli (i.e., general negative-arousing, positive-arousing and neutral words; see Figures 2 and 3). This abnormally enhanced brain activity suggests the presence of a specific difficulty in cognitive inhibition in FM patients (under conditions intimately linked with the core concerns of their disease). However, such supplementary recruitment of neural resources by means same cortical areas only allow them to achieve a comparable behavioural performance to healthy control group during the cognitive inhibition task. These results are in contradiction with those coming from behavioural studies indicating intact cognitive inhibition abilities in FM (Veldhuijzen et al., 2012). A tentative explanation could be related to the idea that brain activity techniques might be more sensitive to detect subtle dysfunctions than behavioural measures alone such as often occurs in FM patients (Glass et al., 2011). Other functional neuroimaging studies have showed that working memory dysfunction (measured through a n-back task) in FM are related to a reduction of neural activity not only at prefrontal regions but also within inferior parietal cortex (IPC) (Seo et al., 2012). It suggests that a different neural activation pattern of the frontoparietal memory network could be explaining, at least partially, cognitive impairments in FM. Diminished early ERP activity of FM patients during a 2-back task has been also detected at inferior parietal sites, Suggesting that problems associated with the early storage of information might be attributable to analtered functioning of parietal areas (Mercado et al.,in preparation). On the other hand, some investigations have indicated the presence of differences associated with the hippocampus activity between patients and healthy control participants (Emad et al., 2008). 


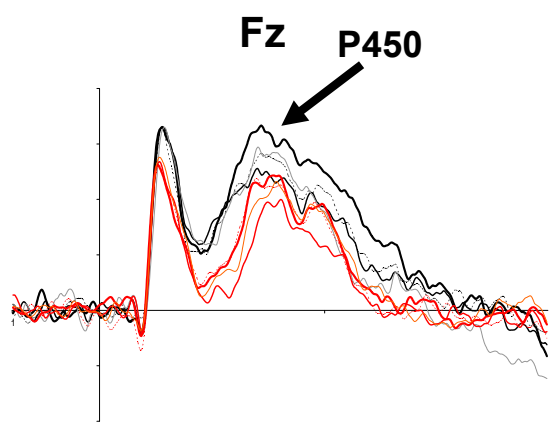

F2

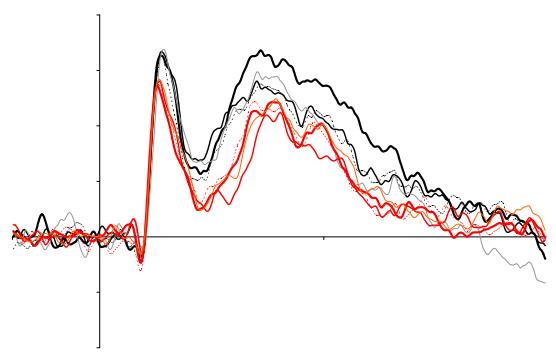

P450

Frontal distribution

F4

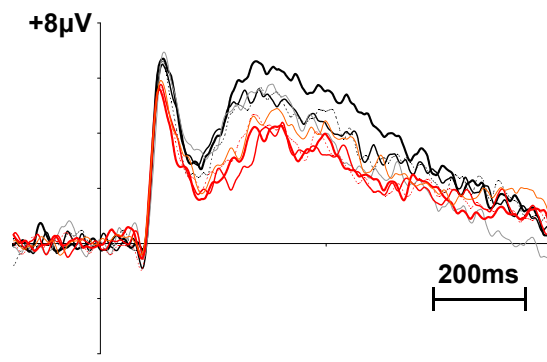

SF/FM
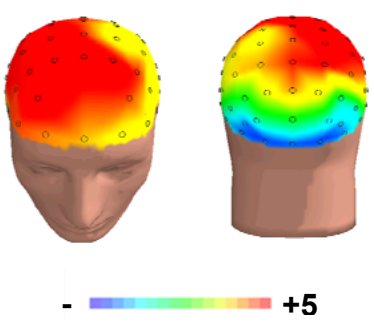

$+5$
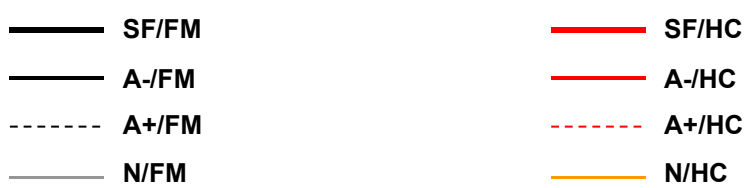

Figure 2. Grand averages of P450 component corresponding to Fibromyalgia (FM) and Healthy control (HC) participants in response to FM symptoms (SF), negative-arousing (A-), positive-arousing $(A+)$ and neutral (N) stimuli. Scales and polarity are shown at F4. 3D maps show topographical distribution of the P450 component. Red areas reflect high activity. 


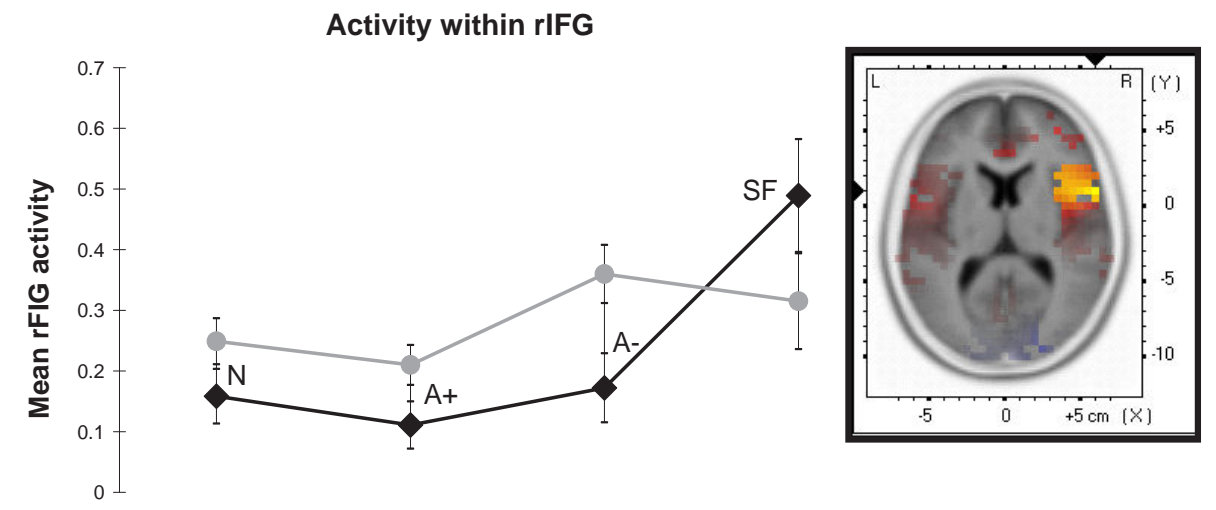

Figure 3. rIFG activity from the emotional Stroop task for patients with fibromyalgia (FM) and healthy control participants (HC). Right side shows SLORETA solutions to non-parametric randomization tests on P450 component. Coronal brain view in MNI305 template, sliced through the region of maximum activity, is illustrated. Left side shows mean rIFG activity for FM patients and HC participants across the four word categories: FM symptoms (SF), negative-arousing (A-), positive-arousing $(\mathrm{A}+)$ and neutral $(\mathrm{N})$ stimuli. Error bars reflect standard errors. Black line represent rlFG activity for FM patients and, grey line, for HC participants.

As mentioned before, cognitive dysfunctions and pain processing may rely on partially overlapping regions in FM patients. As a consequence of this, resources taken up by pain processing may not be available for executive functioning (Glass et al., 2011). Pain level of patients might contribute to this effect over cognition. Neuroimaging techiques represent an opportunity to advance in the comprehension of FM and further studies should be done to delimitate deficits in order to develop better diagnostic and classification criteria of FM patients and to better design neuropsychological interventions oriented to increase their quality of life.

\section{Genetics in fibromyalgia: Pain and cognition}

Genetic predisposition is likely to be an important factor in the development of FM as suggested by several familial studies (Buskila et al., 1996, 2007; Arnold et al., 2004). These studies found that first-degree relatives of patients with FM had lower pain threshold than controls and were 8.5 times more likely to develop FM than relatives of patients with rheumatoid arthritis. The studies also indicated that the relatives of FM patients are more likely to suffer from comorbidities commonly seen in FM, such as mood disorders, irritable bowel syndrome (IBS), temporomandibular disorder (TMD) and headache (Ablin et al., 2008; Buskila et al., 1996, 2007). Identifying the genes responsible for this genetic contribution to risk should provide a better understanding of the complex mechanisms underlying FM and other chronic pain diseases. In recent years, attempts have been made to identify the genes involved in FM 
using candidate gene genetic association studies, which look for differences in the frequency of different polymorphisms between cases and controls, or with a quantifiable trait. The majority of such candidates have been genes involved in catecholaminergic or serotonergic neurotransmission, including receptors and transporters for dopamine, serotonin, norepinephrine, and epinephrine, as well as the catabolic enzymes catechol-O-methyltransferase (COMT).

Next we will review, in outline, the main findings made on genes associated with FM. The most widely studied gene to date is Catechol-O-Methyltransferase (COMT), which degrades catecholamines such as dopamine, noradrenaline and adrenalin that are involved in various physiological functions including mood, cognition and stress response (Belfer and Segal, 2011). In particular, a single nucleotide polymorphism (SNP), (rs4680), has received a great deal of attention due its functional implications (Zubieta et al., 2003). This polymorphism causes a substitution from a valina (Val) to a methionine (Met) at amino acid position 158 (Val158Met), leading to a three to four fold reduced activity of the COMT enzyme (Lotta et al., 1995). In 2005, Diatchenko and colleagues described three very common haplotypes consisting of four SNPs (rs6269, rs 4633, rs4818 and rs4680-Val158Met) accounting for 96\% of all haplotypes observed in human populations (Diatchenko et al., 2005). They identified them as low (LPS), average (APS) and high (HPS) pain sensitivity haplotypes, and they found a correlation with much more profound change in COMT activity (up to 20-fold difference).

The met/met genotype of the COMT Val158Met polymorphism has been associated with higher sensitivity in response to pain stimuli and the number of tender points in FM (Cohen et al., 2009) as well as with a high risk for the development of FM (García-Fructuoso et al., 2006; Barbosa et al., 2012). Recently, Martínez-Jauand and colleagues (2013) have shown that the HPS-APS haplotypes are more frequent in FM patients than in healthy controls and that FM patients who possess those genetic combinations displayed an increased sensitivity to experimental pain. These results are in accordance with previous reports showing a strong association between the HPS haplotype and high score on the Fibromyalgia Impact Questionnaire (Vargas-Alarcón et al., 2007). These haplotypes might be associated with increased risk of developing chronic pain disorders (Diatchenko et al., 2005). These data suggest that a decrease of COMT activity might contribute to the maintenance of pain symptoms in FM, and might play a significant role in classifying FM patients (Martínez-Jauand et al., 2013).

COMT variants moderate not only pain but also maladaptive coping processes in patients with FM. Finan and colleagues (2010 and 2011) demonstrated that Met158 allele homozygotes experience more pain in days when pain catastrophizing and pain attention scores were elevated, and a greater decline in positive affect on days when pain was elevated. These findings support the role of COMT and catecholamines in affective reactivity to pain, and in pain-related cognition pathways in patients with FM. A recent study has proposed that the Val158Met can play a relevant role in phenotypic expression of FM. They showed that women with FM and Met/Met genotype had more severe psychological and functional impact scores than those with the $\mathrm{Val} / \mathrm{Val}$ genotype, although the differences were not significant (Desmeules et al., 2012). More recently, Fernández de las Peñas and colleagues (2012) have shown that FM 
patients with Met/Met genotype exhibit higher disability, anxiety and depression than those with $\mathrm{Val} / \mathrm{Val}$ and $\mathrm{Val} / \mathrm{Met}$ genotype.

As indicated above, cognitive dysfunction has been considered as one of the most disturbing symptoms, apart from pain, in patients with FM. Neuropsychological investigations have suggested that executive control and working memory impairments seem to be the key to explain a great part of this cognitive dysfunction in FM (Glass, 2010) and it points out to the existence of an altered neural substrate, presumably within prefrontal regions, such as inferior prefrontal cortex (IPFC), MPFC or ACC (Glass et al., 2011). In this context, it has been shown that more than $60 \%$ of released dopamine is metabolized by COMT in the frontal cortex (Karoum et al., 1994), and that the Val158Met polymorphism affects working memory and executive functions in healthy population (Bruder et al., 2005) and some mental disorders such as schizophrenia (Diaz-Asper et al., 2006; Hosak, 2007). Therefore, COMT may be a good candidate for the study of cognitive impairment in patients with FM.

The endogenous serotonergic system is comprised of the neurotransmitter serotonin $(5-\mathrm{HT})$, multiple serotonin receptors (5-HT2A, 5-HT3A, 5-HT3B) and the serotonin transporter (5HTT). This system is a key contributor to both depression and pain in FM. In fact, serotonin is decreased in FM, and selective serotonin reuptake inhibitors have some efficacy in FM (Gupta and Silman, 2004). Despite the complexity of the serotonergic pathway, research has mainly focused on a limited number of genes. Offenbaecher and colleagues (1999) analyzed the genotypes of the promoter region of the serotonin transporter gene (5-HTT) in patients with FM and healthy controls. A significantly higher frequency of the S/S genotype of the serotonin transporter promoter region was found in FM as compared to healthy participants. The S/S subgroup exhibited higher mean levels of depression and psychological distress. It was suggested that these results support the notion of an altered serotonin metabolism in at least a subgroup of patients with FM (Buskila et al., 2007). These findings were subsequently confirmed by a study analyzing Palestinian Arabs and Israeli Jews (Cohen et al., 2002). However, the study in other candidate genes within the serotonergic system failed to demonstrate a significant difference in the frequency of the polymorphism among FM patients and controls (Bondy et al., 1999; Frank et al., 2004; Matsuda et al., 2010).

The dopaminergic system has also been the target of extensive study in search of the genetic factors related to FM. Dopamine is a crucial neurotransmitter involved in multiple activities including pain transmission and endogenous analgesia (Wood, 2008). A single nucleotide polymorphism (Ser9Gly) in the dopamine-D3 receptor gene predicts changes in pain threshold in FM patients but not in healthy subjects (Potvin et al., 2009). In the FM group, the Ser9Gly polymorphism was a predictor of decreased thermal pain threshold and diffuse noxious inhibitory control (DNIC) efficacy (Potvin et al., 2009). Polymorphisms in the dopamine receptor 4 (DRD4) gene has also been associated with FM. Buskila and colleagues (2004) reported a significant decrease in the frequency of the 7 repeated allele in exon III of the D4 receptor gene in FM patients, who also demonstrated an association between this polymorphism and the low novelty seeking personality trait. This was considered consistent with the personality profile of FM patients, who scored high on anxiety related personality traits and 
low on novelty or sensation seeking. In a study of 384 subjects with DRD4 polymorphism, allele 4 was the most common, occurring in 279 of the 384 subjects (Treister et al., 2009). However, there was no change in cold tolerance, cold perception, cold pain threshold, or heat pain intensity in those subjects compared to subjects with allele 2 or allele 7 (Treister et al., 2009). Dopamine D2 receptor (DRD2) is implicated in different cognitive processes and brain disorder, and polymorphisms in this gene affect gene expression, splicing, and neuronal activity during working memory (Zhang et al., 2007). This has been demonstrated in patients with schizophrenia, whose presence relatively increased density of DRD2 (Laruelle, 1998). Curiously, it has also been observed an increased sensitivity or density of dopamine D2 receptors (DRD2) in FM patients (Malt et al., 2003). Preliminary results in our research group found a significant relationship between promoter SNP (rs12364283) in DRD2 and working memory functioning in FM patients. Specifically, we found significant differences during the performance in both Spatial Span (forward sequence) and n-back tasks. Heterozygotes (TC)FM patients had a lower performance compared to TC-HC in both Spatial Span and n-back tasks. They also perform worse than homozygotes TT-FM patients but only in the Spatial Span task (Gómez-Esquer et al., 2012). Our results suggest that DRD2 could be playing an important role in working memory functioning in FM patients and support the implication of dopaminergic pathways in the cognitive symptoms of FM.

Another candidate gene is the $\beta_{2}$-adrenergic receptor (ADRB2). It mediates physiologic responses such as vasodilation and bronchial smooth-muscle relaxation, and represents a connection between the sympathetic nervous system and the immune system (Small et al., 2003; Catapano \& Mangi, 2007). Alterations in the ADRB2 function have been implicated in several psychiatric and psychological disorders, including those associated with chronic pain (Lee et al., 2012). Vargas-Alarcón and colleagues (2009) reported that having the AC haplotype of the two SNPs (rs1042713 and rs1042714) was associated with an increased risk for suffering FM among Mexican and Spanish individuals. Recently, it has been published the first study to demonstrate ADRB2 polymorphism-related differences in intracellular cyclic Adenosine Monophosphate (cAMP) levels in FM Peripheral Blood Mononuclear Cells (PBMC), before and after ADRB2 stimulation. These findings suggest that ADRB2 polymorphisms may influence the response to a variety of $\beta$-adrenergic ligands and may help to explain some differences in responsiveness of FM subgroups to the adrenergic agonist medication currently approved for FM treatment (Xiao et al., 2011).

Finally, we will briefly discuss about SCN9A, a gene that encodes sodium channel in dorsal root ganglia (DRG). A consistent line of investigation suggests that autonomic nervous system dysfunction may explain the multi-system features of FM. In this context, DRG play a key role in pain perception and sodium channels located in DRG act as molecular gatekeepers of pain detection at peripheral nociceptors. Mutations in this gene have caused severe pain disorders and congenital insensitivity to pain in families, thus demonstrating a critical role in pain processing (Drenth and Waxman, 2007). In FM, Vargas Alarcón and colleagues (2012) demonstrated that, in Mexican women, the frequency of rs6754031 polymorphism of SCN9A was significantly different between FM patients and healthy controls. Interestingly, patients with 
GG genotype had higher Fibromyalgia Impact Questionnaire (FIQ) scores than patients with the GT or TT genotype. These results show that there is an association between the rs 6754031 polymorphism and the risk of developing FM as well as the FIQ score. This association raises the possibility that some patients with severe FM may have a DRG sodium channelopathy (Vargas-Alarcón et al., 2012). However, further investigation will be necessary in other ethnic groups with a large sample size to verify this observation.

Despite the large number of studies examining the potential contribution of the candidate gene polymorphism to FM susceptibility, many studies have produced conflicting results (Potvin et al., 2010; Frank et al., 2004; Gursoy, 2002). The explanation for these results could be that individual studies based on small sample sizes have insufficient power to detect positive associations and they are incapable of demonstrating the absence of such association. Recently, Lee and colleagues (2012) have conducted a systematic meta-analysis of seventeen candidate genes and over 35 polymorphisms were identified in studies on FM susceptibility. This metaanalysis demonstrates that the 5-HT2A receptor $102 \mathrm{~T} / \mathrm{C}$ polymorphism confers susceptibility to FM. In contrast, no association was found between the 5-HTTLPR S/L allele, COMT Val158Met, and susceptibility to FM. However, the authors were aware of the limitations of their meta-analysis since both the number of the studies and the number of the subjects included in such studies were too small. This may have not enough power to explore the association between the candidate gene polymorphism and FM. They could not perform the ethnic-specific meta-analysis to detect associations in ethnic groups due to limited data. They have not been able either to examine whether the candidate gene polymorphisms are associated with clinical features of FM (Lee et al., 2012). Therefore, additional research including large numbers of patients and controls is required to conclude the association of the candidate gene polymorphisms with FM. Another approach being made lately to identify genetic factors involved in FM is the use of a large-scale candidate gene approach (Smith et al., 2012). This is the largest candidate genes association study of the FM to date, analyzing 3,295 SNPs corresponding to $>350$ genes involved in the biological pathways relevant to nociception, inflammation, and mood. This work observed significant differences in allele frequencies between cases and controls for several novel genes: GABRB3 (in the promoter region of the GABA-A $\beta$ receptor gene), TAAR1 (trace amine-associated receptor 1), GBP1 (guanylate binding protein 1), RGS4 (regulator of G-protein signaling 4), CNR1 (CB-1 cannabinoid receptor gene), and GRIA4 (AMPA ionotropic glutamate receptor 4 subunit). Three of these genes, TAAR1, RGS4, and CNRI play roles in the modulation of analgesic pathways (Smith et al., 2012). Variation in these 4 replicated genes may serve as a basis for the development of new diagnostic approaches, and the products of these genes may contribute to the pathophysiology of FM and represent potential target for therapeutic actions.

\section{Conclusions and future directions}

Evidence from FM investigations indicates that psychoneurobiological dysfunctions play a relevant role in the pathophysiology of this multifactorial and still not fully understood syndrome. Specifically, it was suggested that abnormalities in central brain mechanisms are 
crucial in the understanding of chronic pain in FM, having little relevance the involvement of peripheral processing systems. Mechanisms of central sensitization and those involving descending inhibitory pathways, along with abnormalities in neurotransmission regulatory processes, seem to underlie patient's manifestations of hyperalgesia and allodynia, among other pain-related symptoms. Experimental findings also have demonstrated that both morphological and functional brain changes are related to widespread and diffuse pain and cognitive symptoms suffered by patients with FM.

On the other hand, patients with FM are characterized by the presence of difficulties in the processing of information reporting that it constitutes a very disruptive symptom in their everyday functioning. Cognitive disturbances are mainly related to both executive functions and working memory processes. Neuroimaging investigations have found abnormal activity within prefrontal and parietal regions when patients had to face a demanding task of executive control resources. However, many researchers are trying to answer an important question in order to advance in the knowledge on FM. Can cognitive dysfunction in FM be considered as a primary symptom like abnormal pain perception or, by contrast, is it a direct consequence of the structural or functional changes produced by pain? Based on present findings, cognitive dysfunctions and pain processing seem to share brain networks (prefrontal, supplementary motor regions and parietal cortices) and as a consequence of this, resources taken up by pain processing may not be available for executive functioning. Thus, performance in those tasks, which need a recruitment of working memory resources from the frontoparietal brain network to be correctly completed, would be very poor in FM. Neuroimaging techniques represent an opportunity to advance in the comprehension of pain and cognition interactions in FM and further studies should be done to explore such deficits and their interrelations.

Current data support the statement that FM constitutes a real syndrome characterized by the existence of multiple changes into the brain. Future investigations should be projected to extend these findings and to establish comprehensive explanations about: 1) cerebral mechanisms that provoke those changes, 2) its consequences on the functional state of patients and, 3 ) if brain changes constitute a reversible or permanent condition in the brain of FM patients. In this sense, different therapeutic approaches targeted to reverse such changes in the brain (e.g., pharmacological treatments, neuropsychological interventions, transcraneal magnetic stimulation, etc) may be effective and should be explored. The investigation about different genetic polymorphisms is a promising approach that may also help to improve the comprehension of the pathogenesis of this multifactorial and intriguing syndrome.

\section{Acknowledgements}

This work was supported by the grants URJC-CM-2007-1636 from the Universidad Rey Juan Carlos/ComunidadAutónoma de Madrid and PSI2009-08883 from the Ministryof Science and Innovation of Spain. 


\section{Author details}

Francisco Mercado ${ }^{1}$, Paloma Barjola ${ }^{1}$, Marisa Fernández-Sánchez ${ }^{1}$, Virginia Guerra ${ }^{1}$ and Francisco Gómez-Esquer ${ }^{2}$

1 Department of Psychology, Faculty of Health Sciences, Rey Juan Carlos University, Madrid, Spain

2 Department of Anatomy and Human Embryology, Faculty of Health Sciences, Rey Juan Carlos University, Madrid, Spain

\section{References}

[1] Abeles, A., Pillinger, M., Solitar, B. and Abeles, M. (2007). Narrative Review: The Pathophysiology of Fibromyalgia. Annals of Internal Medicine 146, 726-734.

[2] Ablin, J., Neumann, L., Buskila, D. (2008). Pathogenesis of fibromyalgia - A review. Joint Bone Spine 75 (3), 273-279.

[3] Altamura, M., Elveväg, B., Blasi, G., Bertolino, A., Callicott, J.H., Weinberger D.R. et al. (2007). Dissociating the effects of Sternberg working memory demands in prefrontal cortex. Psychiatric Research 154, 103-114.

[4] Ambrose, K.R., Gracely R.H., Glass, J.M. (2012). Fibromyalgia dyscognition: concepts and issues. Rheumatismo 64 (4), 206-215.

[5] Apkarian, A.V., Bushnell, M.C., Treede, R.D., Zubieta, J.K. (2005). Human brain mechanisms of pain perception and regulation in health and disease. European Journal of Pain 9 (4), 463-484.

[6] Arnold, L.M., Crofford, L.J., Mease, P.J., Burgess, S.M., Palmer, S.C., Abetz, L., Martin, S.A. (2008). Patient perspectives on the impact of fibromyalgia. Patient Education and Counseling 73 (1), 114-120.

[7] Arnold, L.M., Hudson, J.I., Hess, E.V., Ware, A.E., Fritz, D.A., Auchenbach, M.B., Starck, L.O., Keck, P.E. Jr. (2004). Family study of fibromyalgia. Arthritis \& Rheumatism 50 (3), 944-52.

[8] Baddeley, A. (2000). The episodic buffer: A new component of working memory? Trends in Cognitive Sciences 4, 417-423.

[9] Baliki, N., Schnitzer, T., Bauer, W. and Apkarian, V. (2011). Brain Morphological Signatures for Chronic Pain. Plos ONE 6 (10), 1-13. 
[10] Baliki, M.N., Geha, P.Y., Apkarian, A.V., Chialvo, D.R. (2008). Beyond feeling: chronic pain hurts the brain, disrupting the default-mode network dinamics. The Journal of Neuroscience 28 (6), 1398-1403.

[11] Barbosa, F.R., Matsuda, J.B., Mazucato, M., de Castro França, S., Zingaretti, S.M., da Silva, L.M., Martinez-Rossi, N.M., Júnior, M.F., Marins, M., Fachin, A.L. (2012). Influence of catechol-O-methyltransferase (COMT) gene polymorphisms in pain sensibility of Brazilian fibromyalgia patients. Rheumatology International 32 (2), 427-430.

[12] Belfer, I., Segall, S. (2011). COMT genetic variants and pain. Drugs Today (Barc). 47 (6), 457-67.

[13] Bennett, R. (2005). Fibromyalgia: present to future. Current Rheumatology Reports 7, 371-376.

[14] Bondy, B., Spaeth, M., Offenbaecher, M., Glatzeder, K., Stratz, T., Schwarz, M., de Jonge, S., Krüger, M., Engel, R.R., Färber, L., Pongratz, D.E., Ackenheil, M. (1999). The T102C polymorphism of the 5-HT2A-receptor gene in fibromyalgia. Neurobiology of Disease 6 (5), 433-9.

[15] Bruder, G.E., Keilp, J.G., Xu, H., Shikhman, M., Schori, E., Gorman, J.M., Gilliam, T.C. (2005). Catechol-O-methyltransferase (COMT) genotypes and working memory: associations with differing cognitive operations. Biological Psychiatry 58 (11), 901-7.

[16] Bunge, S.A., Klingberg, T., Jacobsen, R.B., Gabrieli, J.D.E. (2000). A resource model of the neural basis of executive working memory. Proceedings of the National Academy of Sciences of the United States of America (PNAS) 97 (7), 3573-3578.

[17] Burgmer, M., Pogatzki-Zahn, E., Markus, G., Stüber, C., Wessoleck, E., Heuft, G., and Pfleiderer, B. (2010). Fibromyalgia unique temporal brain activation during experimental pain: a controlled fMRI Study. Journal Neural Transmission 117, 123-131.

[18] Burgmer, M., Pogatzki-Zahn, E., Gaubitz, M. Wessoleck, E., Heuft, G. Pfleiderer, B. (2009). Altered brain activity during pain processing in fibromyalgia. Neuroimage 44 (2), 502-508.

[19] Bushnell, M.C., Apkarian, A.V. (2005). Representation of pain in the brain. In: McMahon S, Koltzenburg M (eds). Textbook of pain, 5th edn. Churchill Livingstone, Philadelphia, pp. 267-289

[20] Buskila, D. (2009). Developments in the scientific and clinical understanding of fibromyalgia. Arthritis Research and Therapy 11 (5), 242-249.

[21] Buskila, D., Cohen, H., Neumann, L., Ebstein, R.P. (2004). An association between fibromyalgia and the dopamine D4 receptor exon III repeat polymorphism and relationship personality traits. Molecular Psychiatry 9 (8), 730-731.

[22] Buskila, D., Neumann, L., Hazanov, I., Carmi, R. (1996). Familial aggregation in the fibromyalgia syndrome. Seminars in Arthritis and Rheumatism 26 (3), 605-11. 
[23] Buskila, D., Sarzi-Puttini, P., Ablin, J.N. (2007). The genetics of fibromyalgia syndrome. Pharmacogenomics 8 (1), 67-74.

[24] Carrillo-de-la-Peña, M.T., Vallet, M., Pérez, M.I., Gómez-Perretta, C. (2006). Intensity Dependence of Auditory-Evoked Cortical Potentials in Fibromyalgia Patients: A Test of the Generalized Hypervigilance Hypothesis. Journal of Pain 7, 480-487.

[25] Catapano, L.A., Manji, H.K. (2007). G protein-coupled receptors in major psychiatric disorders. Biochimica et Biophysica Acta 1768 (4), 976-93.

[26] Ceko, M., Bushnell, C. and Gracely, R. (2012). Neurobiology Underlying Fibromyalgia Symptoms. Pain Research and Treatment 2012, Article ID 585419, 8 pages

[27] Cifre, I., Sitges, C., Fraiman, D., Muñoz, M.A., Balenzuela, P., González-Roldán, A., Martínez-Jauand, M., Birbaumer, N., Chialvo, D.R., Montoya, P. (2012). Disrupted functional connectivity of the pain network in fibromyalgia. Psychosomatic Medicine $74(1), 55-62$.

[28] Cohen, H., Buskila, D., Neumann, L., Ebstein, R.P. (2002). Confirmation of an association between fibromyalgia and serotonin transporter promoter region (5- HTTLPR) polymorphism, and relationship to anxiety-related personality traits. Arthritis \& Rheumatism 46 (3), 845-7.

[29] Cohen, H., Neumann, L., Glazer, Y., Ebstein, R.P., Buskila, D. (2009). The relationship between a common catechol-O-methyltransferase (COMT) polymorphism val(158) met and fibromyalgia. Clinical and Experimental Rheumatology 27 (5), 51-6.

[30] Cook, D.B., Lange, G., Ciccone, D.S., Liu, W.C., Steffener, J. Natelson B.H. (2004). Functional imaging of pain in patients with primary fibromyalgia. Journal of Rheumatology 31 (2), 364-378.

[31] Correa, A., Miró, E., Martínez, P., Sánchez, A. and Lupiáñez, J. (2011). Temporal preparation and inhibitory deficit in fibromyalgia síndrome. Brain and Cognition 75, 211-216.

[32] Craggs, J.G., Staud, R., Robinson, M.E., Perlstein, W.M., Price, D.D. (2012). Effective connectivity among brain regions associated with slow temporal summation of C-fiber-evoked pain in fibromyalgia patients and healthy controls. The Journal of Pain 13 (4), 390-400.

[33] Crombez, G., Van Damme, S., Eccleston, C. (2005). Hypervigilance to pain: An experimental and clinical analysis. Pain 116, 4-7.

[34] Dadabhoy, D., Crofford, L., Spaeth, M., Russell, J. and Clauw, D. (2008). Evidencebased biomarkers for fibromyalgia syndrome. Arthritis Research \& Therapy 10 (211), 1-18. 
[35] Dagher, A., Owen, A. M., Boecker, H., Brooks, D.J. (1999). Mapping the network for planning: A correlational PET activation study with the Tower of London task. Brain 122 (10), 1973-1987.

[36] Desmeules, J., Piguet, V., Besson, M., Chabert, J., Rapiti, E., Rebsamen, M., Rossier, M.F., Curtin, F., Dayer, P., Cedraschi, C. (2012). Psychological distress in fibromyalgia patients: A role for catechol-O-methyl-transferase Val158met polymorphism. Health Psychology 31 (2), 242-249.

[37] Diatchenko, L., Slade, G.D., Nackley, A.G., Bhalang, K., Sigurdsson, A., Belfer, I., Goldman, D., Xu, K., Shabalina, S.A., Shagin, D., Max, M.B., Makarov, S.S., Maixner, W. (2005). Genetic basis for individual variations in pain perception and the development of a chronic pain condition. Human Molecular Genetics 14 (1), 135-43.

[38] Diaz-Asper, C.M., Weinberger, D.R., Goldberg, T.E. (2006). Catechol-O-methyltransferase polymorphisms and some implications for cognitive therapeutics. NeuroRx 3 (1), 97-105.

[39] Dick, B.D., Verrier, M.J., Harker, K.T., and Rashiq, S. (2008). Disruption of cognitive function in fibromyalgia syndrome. Pain 139 (3), 610-616.

[40] Drenth, J.P., Waxman, S.G. (2007). Mutations in sodium-channel gene SCN9A cause a spectrum of human genetic pain disorders. The Journal of Clinical Investigation 117 (12), 3603-3609.

[41] Duschek, S., Werner, N.S., Winkelmann, A. Wankner, S. (2013). Implicit Memory Function in Fibromyalgia Syndrome. Behavioral Medicine 39 (1), 11-16.

[42] Emad, Y., Ragab, Y., Zeinhom, F., El-Khouly, G., Abou-Zeid, A., Rasker, J.J. (2008). Hippocampus dysfunction may explain symptoms of fibromyalgia syndrome. A study with single-voxel magnetic resonance spectroscopy. Journal of Rheumatology 35, 1371-1377.

[43] Fan, P.T. (2004). Fibromyalgia and chronic fatigue syndrome. APLAR Journal of Rheumatology 7 (3), 219-231.

[44] Fayed, N., García-Campayo, J., Magallón, R., Andrés-Bergareche, H., Luciano, JV., Andres, E., Beltrán, J. (2010). Localized 1H-NMR spectroscopy in patients with fibromyalgia: a controlled study of changes in cerebral glutamate/glutamine, inositol, choline, and N-acetylaspartate. Arthritis Research \& Therapy 12 (4), R134.

[45] Fernández-de-Las-Peñas, C., Ambite-Quesada, S., Gil-Crujera, A., Cigarán-Méndez, M., Peñacoba-Puente, C. (2012). Catechol-O-methyltransferase Val158Met polymorphism influences anxiety, depression, and disability, but not pressure pain sensitivity, in women with fibromyalgia syndrome. The Journal of Pain 13 (11), 1068-74.

[46] Finan, P.H., Zautra, A.J., Davis, M.C., Lemery-Chalfant, K., Covault, J., Tennen, H. (2011). COMT moderates the relation of daily maladaptive coping and pain in fibromyalgia. Pain 152 (2), 300-307. 
[47] Finan, P.H., Zautra, A.J., Davis, M.C., Lemery-Chalfant, K., Covault, J., Tennen, H. (2010). Genetic influences on the dynamics of pain and affect in fibromyalgia. Health Psychology 29 (2), 134-142.

[48] Frank, B., Niesler, B., Bondy, B., Späth, M., Pongratz, D.E., Ackenheil, M., Fischer, C., Rappold, G. (2004). Mutational analysis of serotonin receptor genes: HTR3A and HTR3B in fibromyalgia patients. Clinical Rheumatology 23 (4), 338-344.

[49] García-Campayo, J., Fayed, N., (2010). Clinical Magnetic Resonance Neuroimaging in Fibromyalgia. Neuroimaging, Cristina Marta Del-Ben (Ed.), 111-124.

[50] García-Fructuoso, F.J., Lao-Villadóniga, J.I., Beyer, K., Santos, C. (2006). Relationship between COMT gene genotypes and the severity of fibromyalgia. Reumatología Clínica 2 (4), 168-172.

[51] Geisser, M.E., Glass, J.M., Rajcevska, L.D., Clauw, D.J., Williams, D.A., Kileny, P.R., and Gracely, R.H. (2008). A Psychophysical Study of Auditory and Pressure Sensitivity in Patients With Fibromyalgia and Healthy Controls. Journal of Pain 9, 417-422.

[52] Giesecke, T., Gracely, R.H., Williams, D.A., Geisser, M.E., Petzke, F.W. (2005). The relationship between depression, clinical pain, and experimental pain in a chronic pain cohort. Arthritis and Rheumatism 52 (5), 1577-1584.

[53] Glass, J.M., Williams, D.A., Fernández-Sánchez, M.L., Kairys, A., Barjola, P., Heitzeg, M.M., Clauw, D.J., and Schmidt-Wilcke, T. (2011). Executive Function in Chronic Pain Patients and Healthy Controls: Different Cortical Activation During Response Inhibition in Fibromyalgia. The Journal of Pain 12 (12), 1219-1229.

[54] Glass, J.M. (2010). Cognitive dysfunction in fibromyalgia syndrome. Journal of Musculoskeletal Pain 18 (4), 367-372.

[55] Glass, J.M. (2009). Review of cognitive dysfunction in fibromyalgia: a convergence on working memory and attentional control impairments. Rheumatic Diseases Clinics of North America 35 (2), 299-311.

[56] Glass, J.M. (2006). Cognitive dysfunction in fibromyalgia and chronic fatigue syndrome: new trends and future directions. Current Rheumatology Reports 8 (6), 425-429.

[57] Glass, J.M., Park, D.C., Minear, M., and Crofford, L.J. (2005). Memory beliefs and function in fibromyalgia patients. Journal Psychosomatic Research 58, $263-269$.

[58] Glass, J.M., Park, D.C. (2001). Cognitive dysfunction in fibromyalgia. Current Rheumatology Reports 3 (2), 123-127.

[59] Gómez-Esquer, F., Barjola, P., Fernández-Sánchez, M., Mercado, F. (2012). Dopamine D2 receptor polymorphism influence on working memory functioning in Fibromyalgia. 14th World Congress on Pain - International Association for the Study of Pain (IASP) 
[60] González, J.L., Mercado, F., Barjola, P., Carretero, I., Lopez-Lopez, A., Bullones, M.A., Fernandez-Sanchez, M., Alonso, M. (2010). Generalized hypervigilance in fibromyalgia patients: an experimental analysis with the emotional Stroop paradigm. Journal Psychosomatic Research 69, 279-287.

[61] Grace, G., Nielson, W., Hopkins, M. and Berg, M. (1999) . Concentration and Memory Deficits in Patients with Fibromyalgia Syndrome. Journal of Clinical and Experimental Neuropsychology 21 (4), 477-487.

[62] Gracely, R.H., Ambrose, K.R. (2011). Neuroimaging of fibromyalgia. Best Practice and Research: Clinical Rheumatology 25 (2), 271-284.

[63] Gracely, R.H., Geisser, M.E., Giesecke, T., Grant, M.A., Petzke, F. Williams, D.A. et al. (2004). Pain catastrophizing and neural responses to pain among persons with fibromyalgia. Brain 127 (4), 835-843.

[64] Gracely, R.H., Petzke, F., Wolf, J.M., and Clauw, D.J. (2002). Functional magnetic resonance imaging evidence of augmented pain processing in fibromyalgia. Arthritis and Rheumatism 46 (5), 1333-1343.

[65] Graven-Nielsen, T., Aspegren Kendall, S., Henriksson, K.G., Bengtsson, M., Sorensen, J., Johnson, A., Gerdle, B., Arendt-Nielsen, L. (2000). Ketamine reduces muscle pain, temporal summation, and referred pain in fibromyalgia patients. Pain 85, 483-491.

[66] Grisart, J., Van del Linden, M. and Masquelier, E. (2002). Controlled processes and automaticity in memory functioning in Fobromyalgia patienes: relation with emotional distress and hypervigilance. Journal of Clinical and Experimental Neuropsychology 24 (8), 994-1009.

[67] Gupta, A., Silman, A.J. (2004). Psychological stress and fibromyalgia: a review of the evidence suggesting a neuroendocrine link. Arthritis Research \& Therapy 6 (3), 98-106.

[68] Gursoy, S. (2002). Absence of association of the serotonin transporter gene polymorphism with the mentally healthy subset of fibromyalgia patients. Clinical Rheumatology 21 (3), 194-197.

[69] Harris, R.E. (2010). Elevated excitatory neurotransmitter levels in the fibromyalgia brain. Arthritis Research \& Therapy 12 (5), 141.

[70] Harris, R.E., Sundgren, P.C., Craig, A.D., Kirshenbaum, E., Sen, A., Napadow, V., Clauw, D.J. (2009). Elevated insular glutamate in fibromyalgia is associated with experimental pain. Arthritis \& Rheumatism 60 (10), 3146-3152.

[71] Harris, R.E., Sundgren, P.C., Pang, Y., Hsu, M., Petrou, M., Kim, S.H., McLean, S.A., Gracely, R.H., Clauw, D.J. (2008). Dynamic levels of glutamate within the insula are associated with improvements in multiple pain domains in fibromyalgia. Arthritis \& Rheumatism 58 (3), 903-907. 
[72] Herrero, J.F., Laird, J.M., Lopez-García JA. (2000). Wind-up of spinal cord neurones and pain sensation: much ado about something? Progress Neurobiology 61, 169-203.

[73] Hosák, L. (2007). Role of the COMT gene Val158Met polymorphism in mental disorders: a review. European Psychiatry 22 (5), 276-281.

[74] Hsu, M.C., Harris, R.E., Sundgren, P.C., Welsh, R.C., Fernandes, C.R., Clauw, D.J., Williams, D.A. (2009). No consistent difference in gray matter volume between individuals with fibromyalgia and age-matched healthy subjects when controlling for affective disorder. Pain 143 (3), 262-267.

[75] Iannetti, G.D., Mouraux, A. (2010). From the neuromatrix to the pain matrix (and back). Experimental Brain Research 205 (1), 1-12.

[76] Julien, N., Goffaux, P., Arsenault, P., Marchand, S. (2005). Widespread pain in fibromyalgia is related to a deficit of endogenous pain inhibition. Pain 114, 295-302.

[77] Karoum, F., Chrapusta, S.J., Egan, M.F. (1994). 3-Methoxytyramine is the major metabolite of released dopamine in the rat frontal cortex. Journal of Neurochemistry 63 (3), 972-979.

[78] Katz, R.S., Heard, A.R., Mills, M., Leavitt, F. (2004). The prevalence and clinical impact of reported cognitive difficulties (fibrofog) in patients with rheumatic disease with and without fibromyalgia. Journal Clinical Rheumatology 10 (2), 53-58.

[79] Seong-Ho, K, Sang-Hyon, K, Seong-Kyu, K, Eun Jung, N, SeungWoo, H \&SeungJae, L. (2012). Spatial versus verbal memoryimpairments in patientswithfibromyalgia Rheumatology Int 32, 1135-1142

[80] Kosek, E., Hansson, P. (1997). Modulatory influence on somatosensory perception from vibration and heterotopic noxious conditioning stimulation (HNCS) in fibromyalgia patients and healthy subjects. Pain 70, 41-51.

[81] Kuchinad, A., Schweinhardt, P., Seminowicz, D.A., Wood, P.B., Chizh, B.A., and Bushnell, M.C. (2007). Accelerated brain gray matter loss in fibromyalgia patients: premature aging of the brain? The Journal of Neuroscience 27 (15), 4004-4007.

[82] Kwiatek, R., Barnden, L., Tedman, R., Jarrett, R., Chew, J., Rowe, C. and Pile, K. (2000). Regional cerebral blood flow in fibromyalgia: Single-photon-emission computed tomography evidence of reduction in the pontine tegmentum and thalami. Arthritis and Rheumatism 43 (12), 2823-2833.

[83] Landro, N.I., Stiles, T.C., Sletvold, H. (1997). Memory functioning in patients with primary fibromyalgia and major depression and healthy controls. Journal Psychosomatic Research 42 (3), 297-306.

[84] Laruelle, M. (1998). Imaging dopamine transmission in schizophrenia. A review and meta-analysis. The Quarterly Journal of Nuclear Medicine 42 (3), 211-221. 
[85] Lautenbacher, S., Rollman GB. (1997). Possible deficiencies of pain modulation in fibromyalgia. Clinical Journal of Pain 13, 189-196.

[86] Leavitt, F, \&Katz, R.S. (2008). Speed of Mental Operations in Fibromyalgia: A SelectiveNamingSpeedDeficit Journal of Clinical Rheumatology 14 (4), 214-218

[87] Leavitt, F., Katz, R.S. (2006). Distraction as a key determinant of impaired memory in patients with fibromyalgia. The Journal of Rheumatology 33 (1), 127-132.

[88] Lee, Y.H., Choi, S.J., Ji, J.D., Song, G.G. (2012). Candidate gene studies of fibromyalgia: a systematic review and meta-analysis. Rheumatology International 32 (2), 417-426.

[89] Lee, Y.C., Nassikas, N.J., Clauw, D.J. (2011). The role of the central nervous system in the generation and maintenance of chronic pain in rheumatoid arthritis, osteoarthritis and fibromyalgia. Arthritis Research \& Therapy 13 (2), 211-221.

[90] Legrain, V., Iannetti, G.D., Plaghki, L., Mouraux, A. (2011). The pain matrix reloaded: A salience detection system for the body. Progress in Neurobiology 93 (1), 111-124.

[91] Lorenz, J., Minoshima, S., Casey, K.L. (2003). Keeping pain out of mind: the role of the dorsolateral prefrontal cortex in pain modulation. Brain 126 (5), 1079-1091.

[92] Lotta, T., Vidgren, J., Tilgmann, C., Ulmanen, I., Melén, K., Julkunen, I., Taskinen, J. (1995). Kinetics of human soluble and membrane-bound catechol O-methyltransferase: a revised mechanism and description of the thermolabile variant of the enzyme. Biochemistry 34 (13), 4202-4210.

[93] Luerding, R., Weigand, T., Bogdahn, U., and Schmidt-Wilcke, T. (2008). Working memory performance is correlated with local brain morphology in the medial frontal and anterior cingulate cortex in fibromyalgia patients: structural correlates of paincognition interaction. Brain 131 (12), 3222-3231.

[94] Lutz, J., Jäger, L., de Quervain, D., Krauseneck, T., Padberg, F., Wichnalek, M., Beyer, A., Stahl, R., Zirngibl, B., and Morhard, D. (2008). White and gray matter abnormalities in the brain of patients with fibromyalgia: A diffusion-tensor and volumetric imaging study. Arthritis and Rheumatism 58 (12), 3960-3969.

[95] Maestú, C., Cortes, A., Vazquez, J.M., del Rio, D., Gomez-Arguelles, J.M., del Pozo, F., Nevado, A. (2013). Increased brain responses during subjectively-matched mechanical pain stimulation in fibromyalgia patients as evidenced by MEG. Clinical Neurophysiology 124 (4), 752-760.

[96] Malt, E.A., Olafsson, S., Aakvaag, A., Lund, A., Ursin, H. (2003). Altered dopamine D2 receptor function in fibromyalgia patients: a neuroendocrine study with buspirone in women with fibromyalgia compared to female population based controls. Journal of Affective Disorders 75 (1), 77-82. 
[97] Martínez-Jauand, M., Sitges, C., Rodríguez, V., Picornell, A., Ramon, M., Buskila, D., Montoya, P. (2013). Pain sensitivity in fibromyalgia is associated with catechol-Omethyltransferase (COMT) gene. European Journal of Pain 17 (1), 16-27.

[98] Martínez-Lavín M. (2004). Fibromyalgia as a sympathetically maintained pain syndrome. Current Pain Headache Reports 8, 385-389.

[99] Matsuda, J.B., Barbosa, F.R., Morel, L.J., et al. (2010). Serotonin receptor (5-HT 2A) and catechol-O-methyltransferase (COMT) gene polymorphisms: triggers of fibromyalgia? Revista Brasileira de Reumatologia 50 (2), 141-149.

[100] Mease, P.J., Arnold, L.M., Crofford, L.J., Williams, D.A., Russell, I.J., Humphrey, L., Abetz, L., and Martin, S.A. (2008). Identifying the clinical domains of fibromyalgia: contributions from clinician and patient Delphi exercises. Arthritis \& Rheumatism 59, 952-960.

[101] Mercado, F., Gonzalez, J.L., Barjola, P., Fernández-Sánchez, M., López-López, A., Alonso, M., and Gómez-Esquer, F. (in press). Brain correlates of cognitive inhibition in Fibromyalgia: Emotional intrusion of symptom-related words. International Journal of Psychophysiology.

[102] Mercado, F., Barjola, P., Fernández-Sánchez, M., Dragoi, D., Fresno, V., Cardoso, S., Gómez-Esquer, F. (submitted). Evidence of altered working memory processes in fibromyalgia patients: an event-related potential study. Pain

[103] Montoya, P., Sitges, C., García-Herrera, M., Izquierdo, R., Truyols, M., Blay, N., and Collado, D. (2005) Abnormal Affective Modulation of Somatosensory Brain Processing Among Patients With Fibromyalgia. Psychsomatic Medicine 67, 957-963.

[104] Montoya, P., Larbig, W., Braun, C., Preissl, H., Birbaumer, N. (2004). Influence of Social Support and Emotional Context on Pain Processing and Magnetic Brain Responses in Fibromyalgia. Arthritis \& Rheumatism 50 (12), 4035-4044.

[105] Munguia-Izquierdo, D., Legaz-Arrese, A., Moliner-Urdiales, D., Reverter-Masia, J. (2008). Neuropsychological performance in patients with fibromyalgia syndrome: relation to pain and anxiety. Psicothema 20, 427-431.

[106] Muñoz-Céspedes, J.M., Tirapu-Ustárroz, J. (2001). Rehabilitación Neuropsicológica. Ed. Síntesis.

[107] Napadow, V., Kim, J., Clauw, D. and Harris, R. (2012) Decreased Intrinsic Brain Connectivity Is Associated With Reduced Clinical Pain in Fibromyalgia. Arthritis \& Rheumatism, 64 (7), 2398-2403.

[108] Napadow, V., LaCount, L., Park, K., As-Sanie, S., Clauw, D.J., Harris, R.E. (2010). Intrinsic brain connectivity in fibromyalgia is associated with chronic pain intensity. Arthritis and Rheumatism 62 (8), 2545-2555. 
[109] Okifuji, A., Turk, DC. (2002). Stress and psychophysiological dysregulation in patients with fibromyalgia syndrome. Applied Psychophysiology and Biofeedback 27, 129-141.

[110] Offenbaecher, M., Bondy, B., de Jong, S., Glatzeder, K., Kruger, M., Schoeps, P., Ackenheil, M. (1999). Possible association of fibromyalgia with a polymorphism in the serotonin transporter gene regulatory region. Arthritis and Rheumatism 42 (11), 2482-2488.

[111] Park, D.C., Glass, J.M., Minear, M., Crofford, L.J. (2001). Cognitive function in fibromyalgia patients. Arthritis \& Rheumatism 44 (9), 2125-2133.

[112] Peyron, R., Laurent, B., García-Larrea, L. (2000). Functional imaging of brain responses to pain. A review and meta-analysis. Neurophysiologie Clinique 30 (5), 263-288.

[113] Potvin, S., Larouche, A., Normand, E., de Souza, J.B., Gaumond, I., Grignon, S., Marchand, S. (2009). DRD3 Ser9Gly polymorphism is related to thermal pain perception and modulation in chronic widespread pain patients and healthy controls. The Journal of Pain 10 (9), 969-975.

[114] Potvin, S., Larouche, A., Normand, E., de Souza, J.B., Gaumond, I., Marchand, S., Grignon, S. (2010). No relationship between the ins del polymorphism of the serotonin transporter promoter and pain perception in fibromyalgia patients and healthy controls. European Journal of Pain 14 (7), 742-746.

[115] Price, D.D., Staud, R., Robinson, M.E., Mauderli, A.P., Cannon, R., Vierck, C.J. (2002). Enhanced

temporal summation of second pain and its central modulation in fibromyalgia patients. Pain 99, 49-59.

[116] Pujol, J., López-Solá, M., Ortiz, H., Vilanova, J.C., Harrison, B.J. Yücel, M., SorianoMas, C., Cardoner, N. Deus, J. (2009). Mapping brain response to pain in fibromyalgia patients using temporal analysis of fMRI. PLoS One 4 (4), e5224.

[117] Reyes del Paso G.A., Pulgar A., Duschek S., Garrido S. (2012). Cognitive impairment in fibromyalgia syndrome: the impact of cardiovascular regulation, pain, emotional disorders and medication. European Journal of Pain 16, 421-429.

[118] Robinson, M.E., Craggs, J.G., Price, D.D., Perlstein, W.M., Staud, R. (2011). Gray matter volumes of pain-related brain areas are decreased in fibromyalgia syndrome. The Journal of Pain 12 (4), 436-443.

[119] Rolls, E.T., O’Doherty, J., Kringelbach, M.L., Francis, S., Bowtell, R., McGlone, F. (2003). Representations of pleasant and painful touch in the human orbitofrontal and cingulate cortices. Cerebral Cortex 13 (3), 308-317.

[120] Russell, I.J., Orr, M.D., Littman, B., Vipraio, G.A., Alboukrek, D., Michalek, J.E., et al. (1994). Elevated cerebrospinal fluid levels of substance $P$ in patients with the fibromyalgia syndrome. Arthritis and Rheumatism 37, 1593-1601. 
[121] Russell, I.J., Vaeroy, H., Javors, M., Nyberg, F. (1992). Cerebrospinal fluid biogenic amine metabolites in fibromyalgia/fibrositis syndrome and rheumatoid arthritis. Arthritis and Rheumatism 35, 550-556.

[122] Sawamoto, N., Honda, M., Okada, T., Hanakawa, T., Kanda, M., Fukuyama, H., Konishi, J., Shibasaki, H. (2000). Expectation of pain enhances responses to nonpainful somatosensory stimulation in the anterior cingulate cortex and parietal operculum/ posterior insula: an event-related functional magnetic resonance imaging study. The Journal of Neuroscience 20 (19), 7438-7445.

[123] Schmidt-Wilcke, T., Clauw, D.J. (2010). Pharmacotherapy in fibromyalgia (FM) - Implications for the underlying pathophysiology. Pharmacology \& Therapeutics 127 (3), 283-294.

[124] Schmidt-Wilcke, T., Luerding, R., Weigand, T., Jürgens, T., Schuierer, G., Leinisch, E., Bogdahn, U. (2007). Striatal grey matter increase in patients suffering from fibromyalgia - a voxel-based morphometry study. Pain 132 (1), 109-116.

[125] Schweinhardt, P., Sauro, K.M. Bushnell, C. (2008). Fibromyalgia: a disorder of the brain? The Neuroscientist 14 (5), 415-421.

[126] Seminowicz, D.A., Davis, K.D. (2007). Pain enhances functional connectivity of a brain network evoked by performance of a cognitive task. Journal of Neurophysiology 97 (5), 3651-3659.

[127] Seo., J. Kim, S.H., Kim, Y.T., Song, H.J., Lee, J.J., Kim, S.H., Han, S.W., Nam, E.J., Kim, S.K., Lee, H.J., Lee, S.J., Chang, Y. (2012). Working memory impairment in fibromyalgia patients associated with altered frontoparietal memory network. PLoS One 7 (6), e37808.

[128] Singer, T., Seymour, B., O’Doherty, J., Kaube, H., Dolan, R.J., Frith, C.D. (2004). Empathy for pain involves the affective but not sensory components of pain. Science 303 (5661), 1157-1162.

[129] Small, K.M., McGraw, D.W., Liggett, S.B. (2003). Pharmacology and physiology of human adrenergic receptor polymorphisms. Annual Review of Pharmacology and Toxicology 43, 381-411.

[130] Smith, S.B., Maixner, D.W., Fillingim, R.B., Slade, G., Gracely, R.H., Ambrose, K., Zaykin, D.V., Hyde, C., John, S., Tan, K., Maixner, W., Diatchenko, L. (2012). Large candidate gene association study reveals genetic risk factors and therapeutic targets for fibromyalgia. Arthritis and Rheumatism 64 (2), 584-93.

[131] Solberg, L., Carlson, C., Crofford, L., Leeuw, R. and Segerstrom, S. (2010). Self-regulatory deficits in fibromyalgia and temporomandibular disorders. Pain 151, 37-44.

[132] Stahl, S.M. (2009). Fibromyalgia - pathways and neurotransmitters. Human Psychopharmacology and Clinical Experiment 24 (1), 11-17. 
[133] Staud, R., Price, D.D., Robinson, M.E., Mauderli, A.P., Vierck, C.J. (2004). Maintenance of windup of second pain requires less frequent stimulation in fibromyalgia patients compared to normal controls. Pain 110 (3), 689-696.

[134] Staud, R. Cannon R.C., Mauderli, A.P., Robinson, M.E., Price, D.D., Vierck, C.J., Jr. (2003). Temporal summation of pain from mechanical stimulation of muscle tissue in normal controls and subjects with fibromyalgia syndrome. Pain 102, 87-95.

[135] Suhr, J. (2003). Neuropsychological impairment in fibromyalgia Relation to depression, fatigue, and pain. Journal of Psychsomatic Research 55, 321-329.

[136] Tagliazucchi, E., Balenzuela, P., Fraiman, D., Chialvo, D.R. (2010). Brain resting state is disrupted in chronic back pain patients. Neuroscience letters 485 (1), 26-31.

[137] Thieme, K., Spies, C., Sinha, P., Turk, D.C., Flor, H., 2005. Predictors of pain behaviors in fibromyalgia syndrome. Arthritis and Rheumatism 53, 343-350.

[138] Tracey, I., Johns, E. (2010). The pain matrix: reloaded or reborn as we image tonic pain using arterial spin labelling. Pain 148 (3), 359-360.

[139] Tracey, I., Mantyh P.W. (2007). The cerebral signature for pain perception and its modulation. Neuron 55 (3), 377-391.

[140] Treister, R., Pud, D., Ebstein, R.P., Laiba, E., Gershon, E., Haddad, M., Eisenberg, E. (2009). Associations between polymorphisms in dopamine neurotransmitter pathway genes and pain response in healthy humans. Pain 147 (1-3), 187-193.

[141] Valdés, M., Collado, A., Bargalló, N., Vázquez, M., Rami, L., Gómez, E., Salamero, M. (2010). Increased glutamate/glutamine compounds in the brains of patients with fibromyalgia: a magnetic resonance spectroscopy study. Arthritis and Rheumatism 62 (6), 1829-1836.

[142] Valet, M., Sprenger, T., Boecker, H., Willoch, F., Rummeny, E., Conrad, B., Erhard, P., Tolle, TR. (2004). Distraction modulates connectivity of the cingulo-frontal cortex and the midbrain during pain - an fMRI analysis. Pain 109 (3), 399-408.

[143] Vargas-Alarcón, G., Álvarez-León, E., Fragoso, J.M., Vargas, A., Martínez, A., Vallejo, M., Martínez-Lavín, M. (2012). A SCN9A gene-encoded dorsal root ganglia sodium channel polymorphism associated with severe fibromyalgia. BMC Musculoskeletical Disorders 20, 13-28.

[144] Vargas-Alarcón, G., Fragoso, J.M., Cruz-Robles, D., Vargas, A., Martínez, A., Lao-Villadóniga, J.I., García-Fructuoso, F., Vallejo, M., Martínez-Lavín, M. (2009). Association of adrenergic receptor gene polymorphisms with different fibromyalgia syndrome domains. Arthritis and Rheumatism 60 (7), 2169-2173.

[145] Vargas-Alarcón, G., Fragoso, J.M., Cruz-Robles, D., Vargas, A., Vargas, A., Lao-Villadóniga, J.I., García-Fructuoso, F., Ramos-Kuri, M., Hernández, F., Springall, R., Bojalil, R., Vallejo, M., Martínez-Lavín, L. (2007). Catechol-O-methyltransferase gene 
haplotypes in Mexican and Spanish patients with fibromyalgia. Arthritis Research \& Therapy 9 (5), R110.

[146] Veldhuijzen, D., Sondaal, S. and Oosterman, J. (2012). Intact Cognitive Inhibition in Patients With Fibromyalgia but Evidence of Declined Processing Speed. The Journal of Pain 13 (5), 507-515.

[147] Verdejo-Garcia, A., Lopez-Torrecillas, F., Calandre, E.P., Delgado-Rodriguez, A., Bechara, A. (2009). Executive function and decision-making in women with fibromyalgia. Archives of Clinical Neuropsychology 24 (1), 113-122.

[148] Vierck, C.J. (2006). Mechanisms underlying development of spatially distributed chronic pain (fibromyalgia). Pain 124 (3), 242-263.

[149] Walteros, C., Sánchez-Navarro, J.P., Muñoz, M.A., Martínez-Selva, J.M., Chialvo, D., and Montoya, P. (2011). Altered associative learning and emotional decision making in fibromyalgia. Journal of Psychosomatic Research 70 (3), 294-301.

[150] Wiech, K., Seymour, B., Kalisch, R., Stephan, K.E., Koltzenburg, M., Driver, J., Dolan, R.J. (2005). Modulation of pain processing in hyperalgesia by cognitive demand. Neuroimage 27 (1), 59-69.

[151] Wiech, K, Ploner, M, \& Tracey, I. (2008). Neurocognitive aspects of pain perception. Cell 12 (8), 306-313

[152] Williams, D.A., Clauw, D.J., Glass, J. (2011). Perceived Cognitive Dysfunction in Fibromyalgia Syndrome. Journal of Musculoskeletal Pain 19 (2), 66-75.

[153] Woolf, C.J. (2004). Pain: moving from symptom control toward mechanism-specific pharmacologic management. Annual International Medicin, 140, 441-451.

[154] Wolfe, F., Clauw, D.J., Fitzcharles, M.A., Goldenberg, D.L., Katz, R.S., Mease, P., Russell, A.S., Russell, I.J., Winfield, J.B., Yunus, M.B. (2010). The American College of Rheumatology preliminary diagnostic criteria for fibromyalgia and measurement of symptom severity. Arthritis Care \& Research (Hoboken) 62 (5), 600-610.

[155] Wolfe, F., Smythe, H.A., Yunus, M.B., Bennett, R.M., Bombardier, C., Goldenberg, D.L., Tugwell, P., Campbell, S.M., Abeles, M., Clark, P. (1990). The American College of Rheumatology 1990 Criteria for the Classification of Fibromyalgia. Report of the Multicenter Criteria Committee. Arthritis and Rheumatism 33 (2), 160-172.

[156] Wood, P.B., Glabus, M.F., Simpson, R., Patterson, J.C., 2nd. (2009). Changes in gray matter density in fibromyalgia: correlation with dopamine metabolism. The Journal of Pain 10 (6), 609-618.

[157] Wood, P.B. (2008). Role of central dopamine in pain and analgesia. Expert Review of Neurotherapeutics 8 (5), 781-797.

[158] Wood, P.B., Patterson, I., James, C., Sunderland, J.J., Tainter, K.H., Glabus, M.F., Lilien, D.L. (2007b). Reduced presynaptic dopamine activity in fibromyalgia syndrome 
demonstrated with positron emission tomography: a pilot study. The Journal of Pain $8(1), 51-58$.

[159] Wood, P.B., Schweinhardt, P., Jaeger, E., Dagher, A., Hakyemez, H., Rabiner, E.A., Bushnell, M.C., Chizh, B.A. (2007a). Fibromyalgia patients show an abnormal dopamine response to pain. The Journal of Neuroscience 25 (12), 3576-3582.

[160] Xiao, Y., He, W., Russell, I.J. (2011). Genetic polymorphisms of the beta2-adrenergic receptor relate to guanosine protein-coupled stimulator receptor dysfunction in fibromyalgia syndrome. The Journal of Rheumatology 38 (6), 1095-1103.

[161] Zhang, Y., Bertolino, A., Fazio, L., Blasi, G., Rampino, A., Romano, R., Lee, M.L., Xiao, T., Papp, A., Wang, D., Sadée, W. (2007). Polymorphisms in human dopamine D2 receptor gene affect gene expression, splicing, and neuronal activity during working memory. Proceedings of the National Academy of Sciences of the United States of America 104 (51), 20552-20557.

[162] Zubieta, J.K., Heitzeg, M.M., Smith, Y.R., et al. (2003). COMT val158met genotype affects mu-opioid neurotransmitter responses to a pain stressor. Science 299 (5610), 1240-1243. 